\title{
The psychological reality of phonemes
}

\author{
BRANKY ZEI \\ University of Geneva
}

(Received 28 December 1977)

\section{INTRODUCTION}

The subject's cognitive activity can lead to the construction and elaboration of two kinds of concepts: physical (e.g. the concept of a cube, a tree, a table, etc.) and logico-mathematical (e.g. the concept of natural numbers). Both kinds of concepts are constructed through the subject's actions performed on real objects. Thus a child acquires the physical knowledge of a cube by manipulating it. The physical concept of a cube implies knowledge of its inherent properties, and it is through action that children discover the inherent properties of objects. In other words, objects show their inherent properties by yielding to some actions and resisting others (e.g. a cube will resist the attempt of being rolled).

In comparison with this, the construction and elaboration of the knowledge of one's own vocalizations seems to be somewhat specific. While objects in general may offer resistance to certain actions performed on them, sounds (as acoustic objects) produced by the cognizing subject himself, do not. Further, any major change in articulatory phonetic activity generally involves a change in the acoustic properties of sounds; by contrast, other objects do not change their properties according to the activities exercised upon them. Right from birth, the child's auditory sensations of his own vocalizations coincide with, or shortly follow, his own articulatory phonetic activity. It is well known that children's first imitations of the sounds produced by other people are restricted to those sounds that are part of the children's own repertory, and in general children seem to recognize only those sounds that can be associated with their own articulatory capabilities. This means that their concepts of speech sounds as acoustic objects imply the knowledge of both acoustic and articulatory properties.

Instrumental techniques can doubtless yield findings which provide an insight into the speaker's articulatory activity. But such findings cannot ultimately determine which of the observed phenomena appear as relevant for speech production to a naive subject, and they are of no great help in determining the size of the discrete units involved in speech production either. Finding out what knowledge a naive subject has of his own articulatory activity is likely to shed

[*] This work was done with the help and encouragement of Professor Hermine Sinclair and herewith I express my deepest thanks to her. The subjects were pupils at the International School of Geneva, Bellevue Annex, and I would like to express my sincerest thanks to Diana Maple, the Headmistress of the school, for making the experiment possible.

$0305-0009 / 79 / 0622-0005 \$ 01.50$ (C) 1979 Cambridge University Press. 


\section{CHILD LANGUAGE}

much more light on the psychological basis of speech production. The following experiment was therefore carried out to obtain some information as to $(a)$ the nature of the awareness children have of their own articulatory activity, and $(b)$ the level of mental development at which this awareness appears.

\section{METHOD}

Children were interviewed, to discover their awareness of their own articulatory activity involved in the production of certain phonemes, either isolated or incorporated in words. The subjects were 30 children, in five groups of six per year of age, from 5 to 9. The children's first language was English, and they all came from the same socio-economic middle-class background.

\section{Procedure}

In the first part of the interview, the children were asked a number of questions, preceded by the following remarks.

I am going to ask you a few questions and I would like you to tell me exactly what you think. Whatever you say will be correct, i.e. there are no wrong answers. Even if you say 'I don't know', it will be a correct answer for me. Let's now stop talking for a moment and be quiet:

After a pause of about ro seconds the following questions were asked:

(I) When we don't speak we don't feel anything happening inside ourselves. Is that right?

(2) But when we speak. . [pause left for the child to finish the sentence; if the child did not finish the sentence, the interviewer continued] we feel something inside ourselves.

The interviewer then asked the question 'What do you feel when you say [ə]?'

(3) What do you feel when you say [s]?

(4) What do you feel when you say [g ə]?

(5) What do you feel when you say [i:]?

(6) What do you feel when you say [bə]?

(7) What do you feel when you say [o:]?

(8) Suppose that I don't know how to say [tə] and you want to teach me how to do it. Tell me what I must do to say [tə].

Since in their answers the children often described given sounds as 'noises' they were asked the following question:

(9) Do you make all these noises when you talk? 
The second part of the interview, which took place one month later, consisted of the following questions:

(I) Teach me how to say [kuk]. Suppose that I can't say it. Tell me what I must do to say [kuk].

(2) Now I am going to say something in a language that you don't understand, and I would like you to tell me if the two things that I'll say are the same thing or not. Listen: [čim] [ćim]. ${ }^{1}$

If the answer was that they were different, the following question was asked:

(3) Do they sound different or do they feel different?

(4) And when I say [t $[\supset: k]$ and [ćo:k] is that the same thing?

\section{RESULTS}

The children used their own words to describe what we may refer as their articulatory sensations, e.g. 'My tummy feels funny', 'It blocks in the neck', 'I feel something jerking'. A representative selection of responses is provided here.

\section{Pierre (5; o) \\ Experimenter}

(2) What do you feel when you say [ə]?

Is that all you feel?

Do you feel anything in your mouth?

(3) And what do you feel when you say [s]?

What do you mean 'at the end'?

And if $I$ asked you to tell me the difference between [a] and [s], what would you say?

And for [s]?

How does it move?

(4) What do you feel when you say [ga]?

Do you feel anything in your mouth?

Does it block in the throat?

(5) And what do you feel when you say [i:]?

Is that all?

\section{Child}

Something moves here.

(Points at the middle of his neck)

Yes, tummy moves.

It goes in only a tiny bit.

No, nothing in the mouth.

Tongue moves at the end.

When we finish the talking it goes in. It goes in and down also at the same time[s].

For [ə] the tummy goes a bit out.

At the end it goes in.

The tongue moves at the end.

The tongue goes up and a little to the teeth.

The tongue goes out at the end and in again.

Here (points at the throat) it blocks.

Yes, it blocks in the throat.

The tip of the lips goes smiling.

The tummy gets a tiny bit fatter.

[1] The two initial sounds which are phonemically distinct in Serbo-Croatian, are acoustically fairly similar. The first one is an apico-alveolar affricate while the second one is a dorso-palato-alveolar affricate. 
(6) What do you feel when you say [bə]?

Is that all?

(7) And when you say [o:]?

Anything else?

Lips touching together. Touching together and in.

Tummy at the end goes in.

Something here (points at the chest). It doesn't block, but here (points at the chest) it goes [ə].

[०:] [०:] Tummy gets a tiny bit fatter. And the mouth goes round; the lips go round.

Catherine $(9 ; 0)$

(2) What do you feel when you say [ə]?

Where do you hold your breath?

(3) What do you feel when you say [s]?

Do you feel anything in your mouth?

What special way?

(4) What do you feel when you say [gə]

When does this noise appear?

What shape is it?

If I put my tongue at the bottom of my bottom teeth will I say [gə]?

What else do you do?

And what about your tummy? Do you feel anything in your tummy?

(5) What do you feel when you say [ii]?

The same as for [go]?

Otherwise everything else is the same; your tongue goes up...

I see, and does the tongue do anything or not?
First of all I feel holding my breath for [2] and before I start I hold my breath and I feel I'm saying [a].

Here (points at the chest).

I feel my breath is going quite quickly; quicker than before.

$\mathrm{Hm}$... [s]. Yes, I feel my tongue is in a special way to make that sound.

It's sort of touching...going straight, I mean half straight and half upwards.

[ga] Oh, first of all it makes a sort of funny noise inside sometimes, and then I say [ge].

When I get my mouth in a shape for saying [ga].

The tip of my tongue comes at the bottom of my bottom teeth. No.

And then the back of the tongue goes up on to the top part.

[ga] Yes, I feel that the funny noise goes down into my tummy. It sort of disappears in my tummy.

Hm...I feel the same sort of thing.

Yes, except that my mouth does a sort of smile or something.

No. No. The tongue doesn't go up in the back but it does go down in the front because my teeth are not straight. They are (she puts her mouth in the position for [i:]).

[ii] Yes it does. It sort of curves in the middle and the two ends touch my teeth....the teeth sides. 
(6) What do you feel when you say [o:]?

(7) Suppose that I don't know how to say [to] and you want to teach me how to do it. Tell me what I must do to say [tə].

Anything else?
These parts of the lips (corners) push in more than the rest of it. My tummy stays still and it feels a bit numb perhaps. [o:] I feel a faint feeling in my neck when $I$ hold my breath to say [o:].

[ta] Well you have to touch the front part of your tongue at the top part of your mouth, and try and let out sound and then open your mouth and let it come out. No, I don't think so.

\section{DISCUSSION}

Reports of articulatory sensations varied with age. However, the following turned out to be the most frequent at all ages. For each sound they are presented in order of frequency, and translated into more technical terms.

\section{'Feeling' responses (part one)}

[ə] sensations in the abdomen vocal cord vibrations breathing out

[s] tongue movements participation of teeth sensations in the abdomen

[gə] velar point of articulation vocal cord vibrations sensations in the abdomen

[ii] free passage sensations in the abdomen participation of lips participation of the tongue

[ba] sensations in the stomach participation of lips the plosive manner of articulation

[o:] free passage participation of lips sensations in the stomach

[ta] point of articulation (very precise and exact) explosive manner of articulation expiration 
All the children answered affirmatively to the question: 'Do you make all these noises when you speak?'

Since the participation of the abdominal muscles was reported for all the above sounds, we can conclude that the movements involved in expiration, phonation and articulation constitute for a naive subject a single complex of tactilo-kinesthetic sensations. It is to be noted that abdominal movements are not mentioned by the children in their 'teaching' responses (cf. below). On the other hand, the children described the point and manner of articulation more precisely for teaching purposes (part two of the interview). On the whole consonants were more precisely described than vowels in terms of both the place and manner of articulation. In particular, degree of opening for vowels did not figure at all in the description of tactilo-kinesthetic sensations.

\section{'Teaching' responses (part two)}

[kuk] In the majority of spontaneous descriptions, the word was treated as a whole, with a beginning and an end. If any phonemic segmentation was given, it was expressed in terms of the beginning and the end of the word. In their instructions the children insisted on the lip shape and the breathing out.

[čim]-[ćim] The two forms were identified as different, and were characterized as both feeling different and sounding different. The difference was described in the following terms:

$\begin{array}{cl}\text { [čim] } & \text { [cim] } \\ \text { bigger } & \text { smaller } \\ \text { louder } & \text { softer } \\ \text { harder } & \text { lighter } \\ \text { longer } & \text { shorter }\end{array}$

[t $\left.\int 0: k\right]$-[co:k] The difference between the two pronunciations of the word 'chalk' was described in the following terms:

\begin{tabular}{ll} 
[tfo:k] & \multicolumn{1}{c}{$[$ co:k] } \\
English & not English \\
right & wrong
\end{tabular}

It is interesting to notice that the terms 'harder' and 'lighter', which were used by the children to describe the difference between [č] and [c]], actually refer to tactilo-kinesthetic sensations. In many cases the children were able to describe the differences in tactilo-kinesthetic terms on simply listening to the experimenter's pronunciation, i.e. without pronouncing the words themselves.

On the whole the results seem to permit the following conclusions:

(I) Children's tactilo-kinesthetic sensations do not strictly (or sometimes at all) refer to the features generally considered as distinctive. 
(2) Awareness of place and manner of articulation increases with age.

(3) At $5 ; 0$ there definitely exists some awareness of the movements involved in speech production.

Finally, the results obtained in this first experiment on the articulatory awareness of young children raise a number of questions, as follows.

How is tactilo-kinesthetic knowledge built up?

What are the smallest tactilo-kinesthetic units of speech for a naive subject?

Does the tactilo-kinesthetic image of a sound differ according to its position in sequential units (such as the syllable)?

Research concerning these problems is currently being carried out. Initially, it seemed doubtful whether questions such as we asked had any sense for young children. It has become absolutely clear, however, not only that children understand the instructions given by the experimenter, but also that they have remarkable insight into their speech production mechanisms. This indicates that an important development in level of awareness has already taken place by the age of 6 ; 0 . 